\title{
La performatividad de género según La hija extranjera o el compromiso político de Najat El Hachmi ${ }^{1}$
}

\section{The performativity of gender according to La hija extranjera or Najat El Hachmi's political commitment}

\author{
Katarzyna Moszczyńska-Dürst \\ Uniwersytet Warszawski \\ k.moszczynska@uw.edu.pl
}

\begin{abstract}
The objective of this article consists in analysing how and to what extent "the psychic life of power" (Butler, 2001) and the "synchronicity of the non-synchronic" (Cros, 2002) organise discourse practices of the hybrid identity (Sabaté, 2014) encoded in Najat El Hachmi's La hija extranjera (2015), a novel written from a marked transcultural and feminist perspective. The protagonist and narrator in first person, a young Catalan woman of Moroccan origin ("the foreign daughter" of the title), is torn between contradictory ideologies, hopes and desires. She is suspended between the Spanish and the Moroccan cultures, between submission and rebellion. Likewise, we will see how the narrator reveals the great political potential of literature that lies in "resignification" (Butler, 2002).
\end{abstract}

Keywords: Najat El Hachmi's fiction, Catalan women writers, hybrid identities, discourses of migration, resignification, AntConc

Si digo feminismo digo libertad. No la libertad de elegir, no la libertad de consumir, no la que consiste en ponerse delante de una estantería llena de opciones y de decantarse por una cualquiera, la que sea, implique lo que implique. No, cuando digo feminismo, cuando digo libertad, me refiero a vivir sin que mi existencia, mi opinión, mi placer y mi dolor valgan menos que la existencia, la opinión, el placer y el dolor de mis hermanos hombres.

(El Hachmi, 2019, p. 9)

\footnotetext{
${ }^{1}$ El artículo es fruto del proyecto de investigación financiado "Tránsfugas y parias modernas: género y exclusión en la cultura popular del s. XXI (FEM2017-83974-P)”.
} 
El proyecto artístico de Najat El Hachmi se caracteriza por tener un alto contenido de consciencia metaliteraria, metalingüística e ideológica, así como por su posicionamiento transcultural y feminista. Su objetivo político consiste en realizar y comentar el proceso de "escribir y leer como otra" - como "paria rebelde", en términos de Eleni Varikas (2017)-, es decir, desde la diferencia relacional y crítica con las masculinidades, nacionalidades e identidades tradicionales y cerradas. Para empezar, fijémonos en que El Hachmi, que aunque nacida en Marruecos fue escolarizada y educada en catalán, realiza un viaje migratorio a la inversa. En sus dos primeras novelas del ciclo, L'últim patriarca (2008) (trad. El último patriarca, 2010) y La filla estrangera (trad. La hija extranjera, 2015), la autora recrea las narraciones conflictivas y contradictorias de la segunda generación de personas migrantes: la suya. En cambio, Mare de llet i mel (2018) (trad. Madre de leche $y$ miel, 2018), última entrega del ciclo hasta la fecha, se acerca a tratar los discursos y las experiencias de la primera generación. Curiosamente, aunque no nos damos cuenta de ello al principio, la segunda y la tercera novela nos cuentan -en parte- la misma historia, asumiendo distintas perspectivas generacionales. Así, la relación entre "la hija (extranjera)" y "la madre (de leche y miel)" la conocemos primero desde la perspectiva de la hija, narradora en primera persona, para después "escuchar" la historia de la vida de la madre. Madre de leche y miel, que tiene la forma de un relato oral que el personaje protagónico dirige a sus hermanas, reivindica la herencia no escrita de las mujeres de generaciones pasadas que nunca aprendieron a escribir y que, por lo tanto, no pudieron plasmar ni sus historias ni el conjunto de sus experiencias en la forma del discurso literario.

Conviene destacar que en los textos literarios de Najat El Hachmi las identidades de género construidas y reconstruidas en un tiempo y espacio concretos se van constituyendo a través de una reiteración constante de modelos canónicos y ex-canónicos de concebir y vivir el mundo como una mujer (Butler, 2002, p. 18), una tradición heredada de generación en generación por abuelas, madres, hijas, nietas, etc. El análisis digital del corpus, que nos permite trazar y co(n)textualizar dichas reiteraciones al descubrir las palabras usadas con más frecuencia, es muy revelador en este sentido. En este artículo me referiré a las prácticas discursivas codificadas en La hija extranjera. Aparte de las palabras funcionales, los términos que aparecen con más frecuencia en la novela remiten directamente a la identidad femenina codificada reiteradamente y de manera performativa en el discurso dominante como esencial, corporal, mater-nal y mater-ial en términos de Luce Irigaray (2009), y que en todo caso es inalterable: madre(s) (348), mujer(es) (198), casa(s) (140), nunca (128),

\footnotetext{
${ }^{2}$ Eleni Varikas retoma el pensamiento de Hannah Arendt (2004) para definir al "paria rebelde" en términos de un sujeto marginado crítico con la lógica cultural dominante y solidario con otras subjetividades marcadas por la discriminación y exclusión. "El orgullo del paria rebelde -arguye la pensadorareside en su exterioridad, que lo aleja del ejercicio de la dominación y se abre sobre una visión crítica de la sociedad que pretende englobar todas las relaciones injustas". (Varikas, 2017, p. 106)
} 
siempre (124), vida(s) (112), mano(s) (99), lengua(s) (90), cabeza(s) (90), marido(s) (72), palabra(s) (70), pañuelo(s) (63), hombre(s) (51), primo(s) (59), mundo(s) (57), cuerpo(s) (49), pelo (43), noche(s) (48), piel (39), familia(s) (62), marroquí(es) (55), calle(s) (48), cara(s) (49), habitación(es) (46), ojos (33), verdad (33), trabajar (30), agua (27), dios (27), hija(s) (32), pan (27), boda(s) (34) y niño(s) (26). ${ }^{3}$ La lingüística computacional nos revela el énfasis puesto en una "vida" condicionada por el rol genérico de "madresposa" (madre, mujer(es)) y en los aspectos corporales (cabeza, mano, cuerpo, pelo, piel, cara, ojos); una vida inscrita para "siempre jamás" en el ámbito del hogar (casa, habitación), familiar (mujer, marido, primo, familia, hija, boda, niños) y de la tradición religiosa y nacional (marroquíes, dios, pañuelo, pan).

El listado de resultados está directamente relacionado con las posturas y tomas de decisión codificadas en la novela. En efecto, lo que más marca la vida de la protagonista es la relación con su madre, así como el papel maternal que la familia y la sociedad esperan que desempeñe y que, al final de la narración, parece ser su destino (no extraña, pues, que "madre" sea la palabra más frecuentemente evocada en el texto, mucho más que el resto de términos que la siguen en el ranking de las palabras más usadas). Desde el principio, la narradora describe a su madre como "una señora con todas las letras. Admirable y admirada siempre, por dentro y por fuera", ya que "su integridad (no solo) es conocida por todas las mujeres de la ciudad", sino que "atraviesa continentes" gracias a las llamadas telefónicas que se hacen cada domingo. Al constatarlo, pronto añade que se trata de todas las marroquíes, porque "al resto de mujeres no le importa la reputación de una inmigrante con pañuelo en la cabeza" (El Hachmi, 2015, p. 19). La novela empieza con un intento fallido de huida de la casa materna por parte de la protagonista. Esto no es sino un gesto desesperado en su deseo de eludir el paradigma de género que la madre encarna, quien le exige mucho y controla con la ayuda de la mirada disciplinadora de sus compatriotas:

He visto una cabeza rizada que se escurría por la puerta y he empezado a preocuparme por si alguien me veía. Algún marroquí, claro, uno de esos que me conocen y siempre saben qué hago, que me observan para después contarse los unos a los otros que me han visto en tal sitio o tal otro, y se lo dicen a sus mujeres y sus mujeres se lo cuentan, hasta que una llega a nuestra casa y saca el tema mientras habla con mi madre como si no le diera mayor importancia: no hay chica más tranquila que la tuya, nunca la vemos haciendo ningún disparate, no habla con nadie. Con «nadie» quieren decir que no hablo con ningún hombre, que, por más que me digan cosas por la calle, por más que me sigan, yo

\footnotetext{
${ }^{3}$ Presento los resultados extraídos de las búsquedas realizadas en el programa AntConc y referidos a la traducción al castellano de la novela original escrita en catalán: La filla estrangera (La hija extranjera, trad. R.M. Prats). Sin embargo, el ranking de las palabras más usadas coincide en ambas versiones.
} 
no les hago nunca caso. Mi reputación es impecable. Mi reputación es la de mi madre. (El Hachmi, 2015, pp. 23-24)

La madre, en un intento desesperado de proteger su "reputación", organiza la boda de su hija (de dieciocho años) con su sobrino. Gracias a este matrimonio concertado entre primos cumplimentará la tarea más importante que su comunidad le tiene prevista: el salvaguardar la honra de su hija. Al analizar el uso de la segunda palabra más frecuente de la novela descubrimos los estereotipos prescriptivos y proscriptivos de género que se esconden tras el concepto de "reputación". En las frases que incluyen el término "mujer(es)" podemos detectar un alto grado de la doxa: son una muestra de cómo, según el pensamiento dominante, la mujer debe o no debe ser. Así, parafraseando los usos exactos de la "norma" en cuestión, la protagonista sufre una presión insoportable para llegar a ser "una mujer como es debido" (El Hachmi, 2015, p. 45); una "mujer como ellas" (El Hachmi, 2015, p. 34); tiene que comportarse "como si ya fuese una mujer, como ella" (El Hachmi, 2015, p. 165), porque "a partir de cierta edad, cuando una ya es mujer, esa posibilidad, la de estar a solas con alguien del otro sexo, deja de existir" (El Hachmi, 2015, p. 58), porque "el problema es si la mujer se comporta como es debido o no" (El Hachmi, 2015 , p. 36) y porque "una mujer sola siempre da que hablar" (El Hachmi, 2015, p. 13) y, ante todo, porque "las buenas mujeres musulmanas [...] debe[n] compor$\operatorname{tar}[\mathrm{se}]$ y vestir[se] de modo que se note que so[n] hijas de sidi, hijas de señor". Debido a "esa fundamental tarea" de la madre que consiste en "convertir[la] en una mujer decente" (El Hachmi, 2015, p. 62), la protagonista decide que tiene que comportarse según las reglas de género preestablecidas. Sin embargo, le resulta muy difícil interiorizar y encarnar la norma; con frecuencia llega a escuchar reproches como este: "Tienes libertades que no ha tenido ninguna mujer en nuestra familia y aún no tienes bastante" (El Hachmi, 2015, p. 193).

Así, el sexo femenino es equivalente en la novela a lo estrictamente normativizado. Se trata de un ideal regulatorio materializado de manera performativa (v. $\mathrm{Bu}-$ tler, 2002), es decir, mediante la repetición constante de consignas ("el problema es si la mujer se comporta como es debido o no"; El Hachmi, 2015, p. 36), de saberes populares ("una mujer debe tener oro, cuánto más, mejor"; El Hachmi, 2015, p. 71), de miradas disciplinarias ("me observan para después contarse los unos a los otros que me han visto en tal sitio o tal otro"; El Hachmi, 2015, p. 23) y prácticas culturales inculcadas e interiorizadas ("llevaba la ropa de mujer casada, la chilaba oscura y un pañuelo"; El Hachmi, 2015, p. 167). Los estereotipos de género, con sus prohibiciones y sus "promesas de la felicidad" (Ahmed, 2010), funcionan aquí, sin duda, como matriz generadora de valores, posturas y límites de lo pensable y lo no pensable. Como advierte Teresa de Lauretis:

[...] el sistema sexo/genero, tanto una construcción sociocultural como un aparato semiótico, es un sistema de representación que confiere significado (identidad, valor, pre- 
stigio, posición en el sistema de parentesco, estatus en la jerarquía social, etc.) a los individuos de una sociedad dada. Si las representaciones de género vehiculan significados que sancionan posiciones sociales diferentes, entonces el representar o el representarse como macho o hembra implica la asunción del conjunto de estos efectos de sentido. (2000, p. 39)

Preocupada por su "reputación” y movida por el amor hacia su madre, la protagonista decide abandonar sus estudios y someterse al matrimonio concertado con su primo. Parece haber decidido acatar la "norma" para convertirse, muy a su pesar, en "una mujer como ellas". Una vez casada, podrá gozar de una mayor libertad y su madre estará más tranquila y contenta, como redimida, de una vez por todas, de su rol de guardiana:

¿El arte de amar? Ya lo practicarás cuando te cases, cuando estés tranquila, sin toda esta gente que, desde hace tanto tiempo, se preocupa por ti, por tu reputación, la de tu madre sola contigo, la de tu virginidad y tu honor. Una vez casada te dejarán tranquila y ya podrás hacer lo que quieras. Trabajar, estudiar, lo que quieras. Ya no tendrás que demostrar nada, cásate y serás libre. Cásate y tu madre será libre. (El Hachmi, 2015, p. 38)

Sin embargo, las observaciones críticas sobre el funcionamiento de la ideología y el proceso de la construcción de género a través de la reiteración no se ciñen a las cuestiones analizadas hasta ahora, estando centradas por un lado en la conducta sexual y en la relación madre-hija, por otro. No nos olvidemos de que la protagonista, como ya nos advierte el título de la novela estudiada, es una "hija extranjera": una narradora en primera persona que se inscribe -escribiendo- en la genealogía de escritoras catalanas. El Hachmi pretende llegar a entender sus propias vivencias rememorando y rearticulando la herencia literaria de su cultura de acogida, para reivindicar su pertenencia a ella según el lema que ya expresó en su famoso ensayo: "yo también soy catalana" (El Hachmi, 2004). De ahí que el texto, además de evidenciar la performatividad represora del sistema sexo/género, nos plantee dos preguntas esenciales: ¿qué sucede si los discursos que nos moldean y nos disciplinan como sujetos -de manera reiterativa y performativa- pertenecen a dos culturas -y dos lenguas- distintas? Y, en relación a esto, ¿en qué radica el poder político de la literatura?

En La hija extranjera existen referencias intertextuales ${ }^{4}$ a las ficciones de Montserrat Roig y Carme Riera, que refieren especialmente a sus textos de los años seten-

\footnotetext{
${ }^{4}$ Aunque en este artículo me centro en los lazos que El Hachmi establece con los textos literarios de Montserrat Roig y Carme Riera, procedentes de la Transición, su narrativa está repleta de intertextos que la vinculan a la literatura catalana, como advierten Alfons Gregori (2017), Cornelia Maul (2017) y Núria Codina (2018), y de forma más notoria a la obra de Mercè Rodoreda, Victor Catalá y Maria Mercè Marçal. También se la relaciona con el panorama internacional, o sea, con los textos de Sandra Cisneros, Zadie Smith, Houaria Kadra Hadjadji, Hafsa Sinaï-Koudil, Assia Djebar, William Faulkner, entre otros.
} 
ta, Ramona, adéu! (Roig, 1972) (trad. Ramona, adiós, 1980) y “Te deix, amor, la mar com a penyora" (1975) (“Te dejo, amor, en prenda el mar", Riera, 1980). Estas ficciones pertenecen al canon de la literatura de la Transición española, pero en la obra de El Hachmi cobran un nuevo significado. La sociocrítica nos ha enseñado a analizar y valorar la "sincronía de lo no-sincrónico", o la "coincidencia de la nocoincidencia", en palabras de Edmond Cros (2002), codificadas en las prácticas discursivas propias de los tiempos de transición de un orden social a otro. Los textos culturales creados en los tiempos de grandes transformaciones sociales son fruto de la coexistencia, en el mismo tiempo y espacio, de ideologías, cosmovisiones, valores y valoraciones residuales y emergentes (v. Moszczyńska-Dürst, 2017). De manera análoga, se podría decir que las literaturas transculturales en general, y la novela de Najat El Hachmi en particular, codifican la existencia de la "sincronía de lo nosincrónico" (Cros, 2002) como un rasgo inherente a las identidades híbridas. Si bien es cierto que la literatura sobre los procesos migratorios de la primera generación relata el encuentro del "yo" con el "otro", o más bien la codificación del "yo" como "otra" (como paria dentro de la cultura de llegada), los textos literarios de la segunda generación, o sea, aquellos creados por los hijos de emigrantes, inscriben la "sincronía de lo no-sincrónico" en el seno del yo enfrentado a unas expectativas contradictorias.

Con su primera mención a Ramona, adiós (1980), la narradora nos cuenta cómo una visita inesperada de unas amigas de su madre interrumpe su lectura de la novela roigiana: “Adiós a Ramona, adiós, aquí Montserrat Roig, aquí las mujeres de mi pueblo. Las presento secretamente y me río mientras cierro el libro y observo a las mujeres parlotear como gallinas" (El Hachmi, 2015, p. 33). A continuación, cuando escucha los dolorosos recuerdos de las mujeres que hablan en bereber, no puede evitar compararlos con los recuerdos de Mundeta Ventura, uno de los personajes protagónicos de Ramona, adiós:

Ahora ya comenzamos a rememorar, cada una desde donde más le apetece, aquellos tiempos, los tiempos remotos de la infancia y la juventud; cada una inicia el recuerdo desde un punto determinado, pero nunca gratuito, porque muy a menudo esconde un dolor íntimo ya cicatrizado. Mientras hablan pienso en la charla apresurada de Mundeta y lamento constatar que nadie reproducirá nunca la charla apresurada de estas señoras en ningún libro, por el simple hecho de que utilizan una lengua que es del todo ajena al papel y se trasmite por el aire sin dejar rastro alguno. (El Hachmi, 2015, p. 35)

Recordemos que Ramón Buckley (1996) le confiere a Ramona, adiós y a los tomos restantes de la trilogía roigiana el nombre de "anti-saga", ya que al centrarse en la vida y la palabra de mujeres la obra codifica "el reverso" de la historia, centrada en lo cotidiano, lo reiterativo y lo cíclico de la experiencia femenina (v. también Broch, 1980, pp. 72-73). Así, El Hachmi rinde homenaje a Roig, para quien la recuperación del testimonio femenino anteriormente silenciado se ha convertido en el 
mayor de sus retos y su más firme compromiso. El párrafo citado anuncia y explica su elección del relato oral para el siguiente tomo del ciclo: Madre de leche y miel (2018), en el cual la autora reconstruye la palabra y la memoria de las mujeres originarias del Rif. Este libro, en el cual "quería hacer memoria de tantas mujeres que ha conocido y que le han contado sus vidas", la autora lo dedica a su madre que "sin saber leer, le ensenó a escribir" (El Hachmi, 2018, dedicatoria). Parafraseando a Dupláa (1996, p. 92), podríamos decir que ambas autoras, Roig y El Hachmi entienden "la historia como una genealogía y la genealogía como un testimonio, que parte de una realidad memorizada", y es por ello que pretenden rescatar del olvido la memoria histórica y la realidad de mujeres, silenciadas en ambas culturas.

Najat El Hachmi no solo se inscribe en la genealogía de autoras catalanas y explica el reto asumido en su siguiente libro. La autora también entabla un diálogo con distintos personajes literarios que se debaten entre posturas, valores e identidades de género opuestos y excluyentes, entre la sumisión y la rebeldía porque, al igual que la protagonista y narradora en primera persona, estos están marcados por la "sincronía de lo no-sincrónico" (Cros, 2002). La segunda mención de Ramona, adiós (1980) no es menos significativa en este aspecto. Cuando la protagonista se va preparando para su boda (concertada) y decide participar en un taller de costura, alguien se acuerda de sus buenas notas de selectividad y le pregunta por las razones que la llevan a aprender a coser:

¿Que qué hago aquí?, pienso. Le podría decir que soy como Mundeta Ventura preparándose el ajuar y que tengo que bordar mis iniciales en las sábanas, que me caso y que por eso vengo a aprender a coser. Pero sería mentira, porque nosotros no preparamos ajuar, ni bordamos, y menos aún letras. Ni siquiera podemos sentirnos enclaustradas en los patios del Eixample. Nada, le digo para hacer tiempo y pensar mi respuesta, quería ver cómo era este taller... (El Hachmi, 2015, p. 89)

En este fragmento, la narradora se instala en el seno de la narrativa -y de la tradición- de la burguesía catalana para marcar su diferencia de clase y de origen y para subrayar un "yo también soy catalana" (El Hachmi, 2004). Asimismo, conviene destacar que se recuerda de Mundeta Ventura, ya que, a pesar de no compartir con ella ni la tradición de preparar el ajuar, ni la clase, ni los orígenes, sí que tienen otros muchos rasgos en común. Recordemos que Mundeta también se debatía entre la rebeldía y la sumisión: durante la época de la Guerra Civil vivió el gran despertar de su vida política, amorosa y sexual. Sin embargo, tras la derrota republicana y el suicidio de su novio, aceptó casarse Joan Claret, influenciada por su madre (tal y como lo hizo el personaje de El Hachmi unas décadas después). Se casó con un hombre que le inculcó miedo y sumisión, convirtiéndola en no más que una sombra de la mujer que antes fue:

Sólo el recuerdo de la guerra la transfiguraba. [...] Sólo en tales ocasiones su voz habitualmente controlada, y sus ojos, siempre sombríos y apagados, adquirían una gran violen- 
cia [...] Pero de costumbre vivía aplastada ante la presencia de su marido. Le tenía miedo y no se esforzaba en ocultarlo ni siquiera delante de los hijos. Parecía como si hubiera cometido un pecado muy grave, algún hecho imperdonable de juventud. (Roig, 1980, pp. 142-143)

El público lector puede adivinar que ese "gran pecado" e "inconfesable secreto" - de acuerdo con el funcionamiento de la doxa en la España franquista- fue el estigma de la honra, el cual Joan Claret utilizó como herramienta de violencia simbólica en contra de su esposa. Usando la terminología de la madre en La hija extranjera, el hombre se aprovechó de su "mala reputación". Así, este lazo intertextual nos permite acercar la ideología imperante en las comunidades de inmigrantes a las normas de conducta sumamente estrictas y de moral doble que existieron en la España de la dictadura. Según esta, la reputación y el reconocimiento social de las mujeres era proporcional al nivel de oposición o "resistencia" a la tentación de la conquista masculina (de ahí la "reputación impecable" de la narradora, que nunca se para a hablar con ningún hombre). La reputación masculina, sin embargo, descansaba sobre la conquista de cuantas más mujeres, quienes, una vez seducidas, son despreciadas y rechazadas.

De ahí que, como afirma Alfons Gregori (2017, p. 170), la narrativa de autoras catalanas de los años sesenta y setenta presenten unos modelos de conducta de género que dotan a las protagonistas de El Hachmi de agencia política en su lucha contra las imposiciones del patriarcado. En efecto, la narradora recuerda a Mundeta, y a otros personajes femeninos paradigmáticos, cuando acompaña a su madre en su viaje a Barcelona y piensa que

la llevaría por la Gràcia de la Colometa, por el Eixample de la Mundeta, a la universidad de Pla y de tantos otros, le enseñaría el mapa que llevo tiempo dibujando con las lecturas donde aparece la ciudad. Podría enseñarle a leer y así, algún día, después de muchos esfuerzos y mucha práctica, podría llegar a leer los libros que a mí me han marcado y por fin entendería mi mundo y vería que, en realidad, no es tan diferente del suyo. (El Hachmi, 2015, p. 115)

Estos mundos no son tan distintos, simplemente pertenecen a otras épocas, lo que evidencia "la sincronía de lo no-sincrónico" (Cros, 2002) de la experiencia de la protagonista, así como la existencia de puentes que se pueden tender entre comunidades diversas, gracias a la lectura y la escritura.

Asimismo, aparte de señalar los vínculos históricos que unen las culturas catalana y marroquí, Najat el Hachmi critica de manera implícita la lógica patriarcal, tan extendida en Occidente. La figura de la mujer musulmana como paria absoluta no solo es objeto de ataques racistas, sino que también se usa y abusa de ella para desactivar la agenda feminista en los países europeos, supuestamente libres del lastre patriarcal. En palabras de Eleni Varikas: 
[...] (las) modernidades aplazadas y las paradojas del progreso [...] nos llevan de nuevo a la tensión central que en el curso de los últimos siglos ha concedido a la figura del paria toda su fuerza polémica: las oposiciones entre oscurantismo y progreso, tradición y modernidad, Oriente y Occidente [...]. Un mito que alcanza hoy en día su apogeo en la desviación de "la emancipación de las mujeres" al servicio de una retórica racista que, ocultando la desigualdad persistente entre hombres y mujeres en el Occidente moderno, transforma dicha desigualdad en rasgo exclusivo de "culturas" atrasadas e inmóviles, donde destaca el Islam. (Varikas, 2017, p. 108)

Si bien Ramona, adiós se cita casi desde el principio de la narración, el cuento de Carme Riera es evocado apenas en el último capítulo, titulado: "Te dejo, madre, un hijo en prenda". No obstante, su mención codifica la decisión culminante y más significativa de la novela: la narradora y protagonista en primera persona no aguanta más la sumisión y se convierte en una "paria rebelde", y "políticamente hablando advierte Arendt- todo paria que no fuera un rebelde se corresponsabilizaría de su propia opresión" (p. 60). Nuestra narradora decide cortar los lazos con su madre y su marido-primo, agentes del patriarcado, e incluso con su hijo recién nacido:

Te dejo, madre, un hijo en prenda. No puedo dejarte la mar, que aquí, en nuestra ciudad de la Plana, no tenemos; si acaso, podría dejarte el frío y la niebla que se aferran a nuestros pasos durante los nueve meses de invierno y el bochorno insoportable de los tres meses de infierno. Te dejo un hijo, que te hará más compañía. [...] No sé cómo se dice en la lengua de mi madre la palabra «prenda», no le encuentro correspondencia, pero le dejo este hijo en prenda. Ya no la dejo sola. Cuando tienes hijos pequeños, dice ella siempre, nunca te falta la compañía. (El Hachmi, 2015, p. 223, 230)

No quiere ser como las protagonistas de "Te dejo, amor", cuya vida ha desembocado en el acatamiento de los patrones establecidos por el sistema sexo/género. Recordemos que los personajes de Riera han renunciado a su amor lésbico, su libertad y su felicidad, por culpa de la presión social y de las "tecnologías de género" interiorizadas. Tampoco quiere ser como Mundeta Ventura, cohibida por la violencia de su matrimonio concertado. Por eso, en vez de repetir sus historias, las reescribe. Gracias a una reelaboración crítica de citas culturales y, ante todo, gracias a la fuerza que le proporciona la literatura, rechaza el rol de la obediente hija y "madresposa" que la sociedad espera que asuma. Como subraya, "la principal diferencia entre las mujeres que se acostumbran al destino que les ha tocado vivir, que se sienten cómodas en su vida matrimonial y no protestan si no es en voz baja con sus amigas, y yo, es que ellas no han leído y yo sí” (El Hachmi, 2015, p. 197).

Como hemos podido observar, recurriendo a una repetición sintomática de dogmas, consignas y citas culturales, Najat El Hachmi desvela los "mecanismos psíquicos del poder" (Butler, 2001) patriarcal que se basa justo en la constante reiteración de formas aceptadas y aceptables de ver y vivir el mundo como una mujer. Sin embargo, su compromiso político no se ciñe a la denuncia de la doxa, sino que 
pretende también conseguir una resignificación radical de las prácticas discursivas, desviando "la cadena de citas hacia un futuro que tenga más posibilidades de expandir la significación misma" (Butler, 2002, p. 47). Concluyendo, es en el proceso de la resignificación subversiva donde la autora concibe el compromiso político de la literatura capaz de ir más allá de las jerarquías de género y de etnia, así como de apostar por una manera distinta de relacionarse con el mundo. Najat El Hachmi cuestiona, pues, la histórica marginación y cosificación que han sufrido las mujeres en el seno de las culturas patriarcales, en este caso la catalana y la marroquí, al entender lo femenino en términos de "el otro del Otro" (Irigaray, 2009, p. 57). 


\section{BIBLIOGRAFÍA}

Arendt, H. (2004). La tradición oculta. Buenos Aires: Paidós.

Broch, À. (1980). Literatura catalana dels anys setanta. Barcelona: Edicions 62.

Buckley, R. (1996). La doble transición. Política y literatura en la España de los años setenta. Madrid: Siglo XXI Ed.

Butler, J. (2001). Mecanismos psíquicos del poder: teorías sobre la sujeción. Madrid: Cátedra.

Butler, J. (2002). Cuerpos que importan: sobre los límites materiales y discursivos del sexo. Buenos Aires: Paidós.

Codina Solà, N. (2018). Verflochtene Welten: Transkulturalität in den Werken von Najat El Hachmi, Pius Alibek, Emine Sevgi Özdamar und Feridun Zaimoğlu. Würzbur: Königshausen \& Neumann.

Crameri, K. (2014). Hybridity and Catalonia Linguistic Borders: the Case of Najat El Hachmi. En F. Sabaté (ed.), Hybrid Identities (271-295). Bern: Peter Lang.

Cros, E. (2002). El sujeto cultural: sociocrítica y psicoanálisis. Montpellier: CERS.

Dupláa, C. (1996). La voz testimonial en Montserrat Roig. Barcelona: Icaria.

El Hachmi, N. (2004). Jo també sóc catalana. Barcelona: Edicions 62.

El Hachmi, N. (2010). El último patriarca. Barcelona: Planeta (versión original: 2008, L'últim patriarca, Barcelona: Planeta).

El Hachmi, N. (2015). La hija extranjera. Barcelona: Planeta (versión original: 2015, La filla estrangera, Barcelona: Planeta).

El Hachmi, N. (2018). Madre de leche y miel. Barcelona: Planeta (versión original: 2018, Mare de llet $i$ mel, Barcelona: Planeta).

El Hachmi, N. (2019). Siempre han hablado por nosotras. Feminismo e identidad. Un manifiesto valiente y necesario. Barcelona: Destino (versión original: 2019, Sempre han parlat per nosaltres, Barcelona: Planeta).

Gregori, A. (2017). Konstrukcja nietypowej autorki we współczesnej Katalonii: Najat El Hachmi w świetle swoich utworów i projekcji medialnej. En M. Loba, B. Luczak, A. Gregori (red.), „Literatury mniejsze” Europy romańskiej 3. Pośród literatur świata (153-179). Poznań: Wydawnictwo Naukowe UAM.

Irigaray, L. (2009). Ese sexo que no es uno. Madrid: Akal.

Lauretis, T. de (2000). Diferencias. Etapas de un camino a través del feminismo. Madrid: Ed. horas y HORAS.

Maul, C.A. (2017). Grenzgängerinnen schreiben Transdifferenz: Terézia Mora, Marie NDiaye, Najat El Hachmi, Ornela Vorpsi. Berlin: Kulturverlag Kadmos Berlin.

Moszczyńska-Dürst, K. (2017). De las intimidades congeladas a los marcos de guerra: amor, identidad y transición en las novelistas españolas. Sevilla: Padilla Libros.

Riera, C. (1980). Palabra de mujer. Barcelona: Laia (versión original: 1975, Te deix, amor, la mar com a penyora, Barcelona).

Roig, M. (1980). Ramona, adiós. Barcelona: Argas Vergara (versión original: 1972, Ramona, adéu!, Barcelona: Educaula62).

Sabaté, F. (ed.) (2014). Hybrid Identities. Bern: Peter Lang.

Varikas, E. (2017). Las escorias del mundo. Figuras del paria. Xalapa: Veracruz, Universidad Veracruzana. 